\title{
Replay at Optical Communications Wavelengths of Holographic Gratings Recorded in the Visible
}

Vincent Toal

Technological University Dublin, vincent.toal@tudublin.ie

Maurice Whelan

Institute for Health and Consumer Protection, Joint Research Centre, Maurice.whelan@jrc.it

Alberto Volcan

Optics Group, Institute for Health and Consumer Protection, Joint Research Centre, 2102 Ispra, Italy

See next page for additional authors

Follow this and additional works at: https://arrow.tudublin.ie/cieocon2

Part of the Optics Commons

\section{Recommended Citation}

Toal, V., Whelan, M. \& Naydenova, I. (2006). Replay at optical communications wavelengths of holographic gratings recorded in the visible. SPIE proceedings of the International Conference on Holography, Optical Recording and Processing of Information, vol. 6252, pg. 31-37. doi:10.1117/12.676497

This Conference Paper is brought to you for free and open access by the Centre for Industrial and Engineering Optics at ARROW@TU Dublin. It has been accepted for inclusion in Conference Papers by an authorized administrator of ARROW@TU Dublin. For more information, please contact arrow.admin@tudublin.ie, aisling.coyne@tudublin.ie,gerard.connolly@tudublin.ie. Funder: Enterprise Ireland 


\section{Authors}

Vincent Toal, Maurice Whelan, Alberto Volcan, Izabela Naydenova, and Suzanne Martin 
2006-01-01

\section{Replay at Optical Communications Wavelengths of Holographic Gratings Recorded in the Visible}

Vincent Toal

Dublin Institute of Technology, vincent.toal@dit.ie

Maurice Whelan

Institute for Health and Consumer Protection, Joint Research Centre, Maurice.whelan@jrc.it

Alberto Volcan

Optics Group, Institute for Health and Consumer Protection, Joint Research Centre, 2102 Ispra, Italy

Izabela Naydenova

Dublin Institute of Technology, izabela.naydenova@dit.ie

Suzanne Martin

Dublin Institute of Technology, suzanne.martin@dit.ie

\section{Recommended Citation}

Toal, V., Whelan, M., Volcan, A., Naydenova, I., Martin, S.: Replay at optical communications wavelengths of holographic gratings recorded in the visible. SPIE proceedings of the International Conference on Holography, Optical Recording and Processing of Information, Vol. 6252, pp.31-37. 2006. 


\title{
Replay at optical communications wavelengths of holographic gratings recorded in the visible
}

\author{
Vincent Toal, Maurice Whelan*, Alberto Volcan*, Izabela Naydenova and Suzanne Martin \\ Centre for Industrial and Engineering Optics, Dublin Institute of Technology, Dublin 8, Ireland \\ *Optics Group, Institute for Health and Consumer Protection, Joint Research Centre, 2102 Ispra, \\ (Va), Italy \\ emailvincent.toal@dit.ie
}

Keywords: holography, diffraction gratings, communication wavelengths

\begin{abstract}
In this paper we report on holographic diffraction gratings recorded at visible light wavelength, which can be probed at telecommunication wavelengths. The recording material is an easily prepared, self-processing photopolymer, all of whose components are water soluble. Transmission gratings of various types, namely unslanted, slanted, totally internally reflecting and Bragg gratings were all fabricated. Diffraction efficiencies at telecommunications wavelengths compare favourably with those obtained in visible light.
\end{abstract}

\section{Introduction}

There is growing interest in the development of low-cost, easily fabricated optical devices. To take one example, in-fibre grating fabrication for various applications, including telecommunications and sensing involves the use of UV lasers and direct writing into the fibre material by means of phase masks of fixed spatial frequency. It would be advantageous to make use of visible laser light which is easier to control, and cheaper, more versatile recording materials. Bragg gratings for wavelength division multiplexing have already been reported in doped and partially polymerized polymethylmethacrylate ${ }^{1}$.

\subsection{Photopolymers}

Photopolymers have long been in use for holography ${ }^{2}$, holographic applications including gratings and other holographic optical elements $(\mathrm{HOE})^{3,4}$ as well as holographic interferometry and recently electronic speckle pattern interferometry ${ }^{5,6}$. Typically a monomer, crosslinking monomer, a dye sensitizer and an electron donor are dispersed in a binder such as polyvinyl alcohol. Layers up to $150 \mu \mathrm{m}$ thick are deposited on glass substrates by gravity settling, dip coating or the use of Mayer bars. After about 24 hours the material is ready for use. Transmission holographic gratings having up to $95 \%$ diffraction efficiency have been obtained using exposures of $90 \mathrm{~mJ} \mathrm{~cm}^{-2}$ in dry layers of up to $125 \mu \mathrm{m}$ in thickness. No post recording processing is required and the grating is fixed by exposure to actinic light.

In order to measure the diffraction efficiency during recording, gratings are simultaneously illuminated at a wavelength to which the dye is insensitive, so that for example a recording at $532 \mathrm{~nm}$ may be illuminated by a low power He-Ne laser, first ensuring that this laser is incident at the correct (Bragg) angle.

The ability to record a grating at one wavelength and probe it at another suggests a number of interesting possibilities, one of which is the use of a hologram as a beamsplitter and combiner in an electronic speckle pattern interferometer $(\text { ESPI })^{6}$. A transmission hologram of the object under investigation was recorded at $532 \mathrm{~nm}$ and the image reconstructed using a laser diode of wavelength $780 \mathrm{~nm}$ by altering the angle of illumination. This image was superimposed on the image of the object in a simple, near common path, out-of-plane sensitive ESPI system. Direct modulation of the laser diode wavelength allows digital phase shifting for fringe analysis, to be implemented. To extend grating illumination to telecommunication wavelengths would allow for further applications of the photopolymer. 


\section{Recording and illumination geometry (reflection gratings)}

In order to record a grating using $532 \mathrm{~nm}$ light, which can be illuminated in a direction normal to the fringe planes and strongly reflect at $1550 \mathrm{~nm}$, a recorded fringe spacing of about $500 \mathrm{~nm}$ is needed, so that the angle between the recording beams must be about $40^{\circ}$ within the photopolymer layer of refractive index 1.5. Fig. 1 shows a number of possible arrangements. The recording beams are of wavelength $\lambda$ and the reading beam has wavelength $\lambda^{\prime}$. All of these were attempted but in all cases the diffraction efficiency of the gratings proved to be only $1 \%$ or less, even at the recording wavelength.

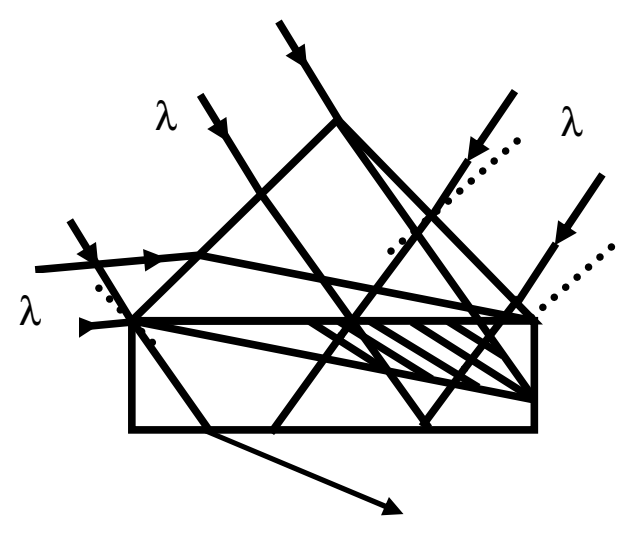

a)

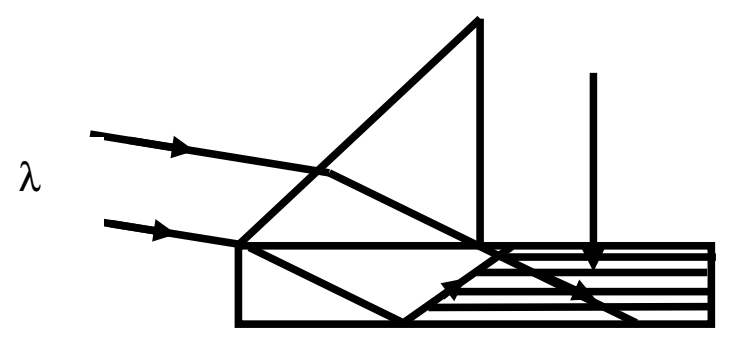

c)

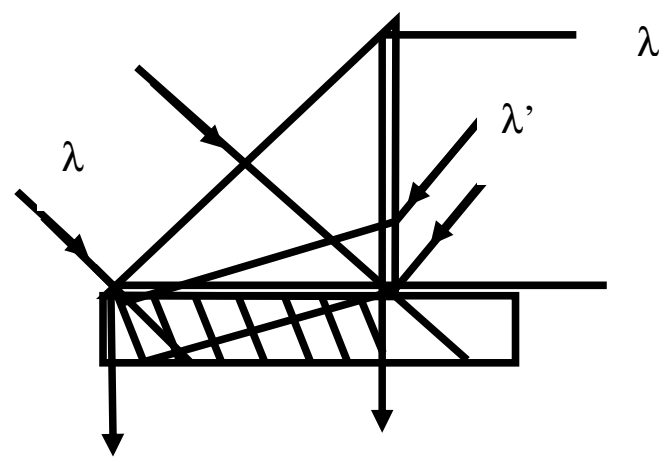

b)

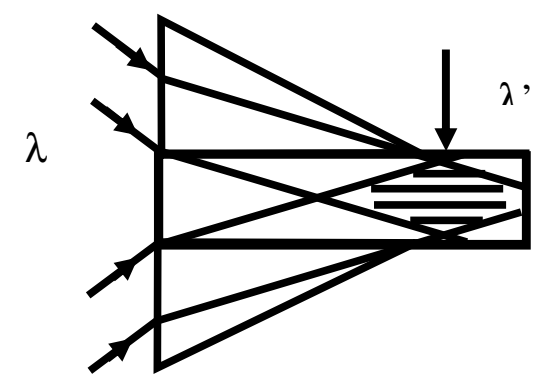

d)

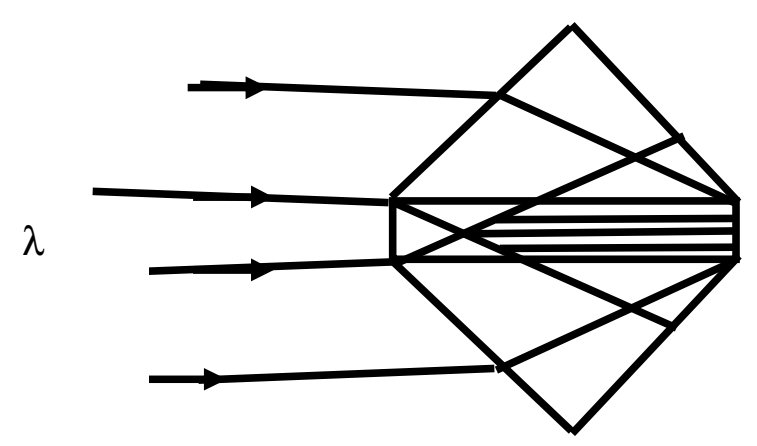

e)

Fig. 1 Arrangements a) to d) permit illumination of the grating at $1550 \mathrm{~nm}$ without removing the prism. c) enables a grating to be recorded with the fringe planes parallel to the layer surface. The angle of incidence of the writing beam is $39^{0}$ to the prism normal so that it is waveguided in the layer, the two resulting beams travelling at $40^{\circ}$ to each other. d) also records a grating vector normal to the layer surface. 1e) shows an arrangement requiring removal of the prisms in order to probe the grating at $1550 \mathrm{~nm}$. 
It is probable that the prism couplers used were inappropriate as they were obtained by cleaving an old cube beamsplitter along its diagonal and optical coatings on the resulting prism hypotenuse faces effectively prevented light from being transmitted into the photosensitive layers.

\section{Recording and illumination geometry (transmission gratings)}

There are a number of possible approaches. These are:

1. unslanted transmission gratings

2. slanted gratings

3. gratings which totally internally reflect at $1550 \mathrm{~nm}$

4. edge-illuminated gratings

\subsection{Unslanted transmission gratings}

The simplest approach is to record an unslanted transmission grating at $532 \mathrm{~nm}$ and illuminate it at $1550 \mathrm{~nm}$ at the appropriate angle (fig. 2). The condition that must be met is

\section{$\sin \theta^{\prime} / \sin \theta=\lambda^{\prime} / \lambda$}

where dashed symbols refer to the illuminating beam $(\sim 1550 \mathrm{~nm}) . \Lambda$, the recorded fringe spacing is given by $\lambda /(2 \sin \theta)$ with $\lambda$ the grating recording wavelength

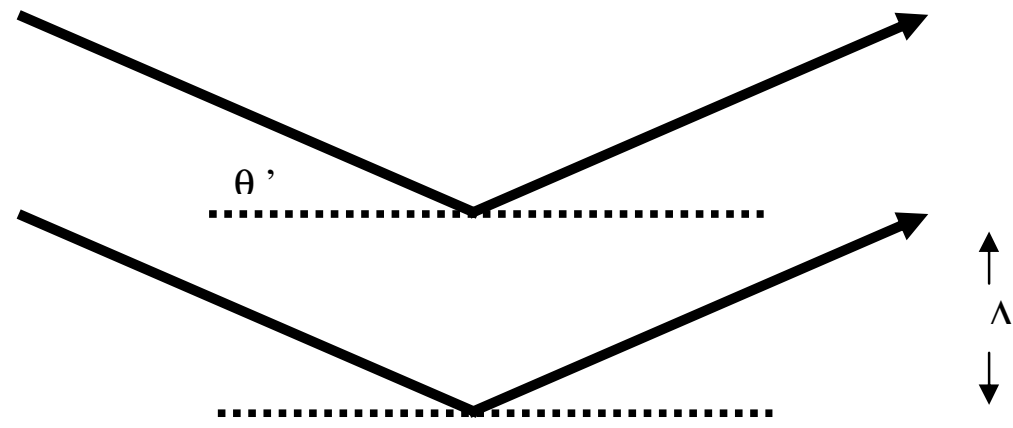

Fig. 2 Reflection of the probe beam from grating planes.

In the extreme case of the $1550 \mathrm{~nm}$ beam at grazing incidence, the writing beams must be incident at angles of not more than $20^{\circ}$ to the normal for a refractive index of 1.5. This because the angles of refraction of these beams are both $13^{0}$ and the value of $\theta^{\prime}$ for the $1550 \mathrm{~nm}$ beam is then $41.6^{0}$, the critical angle. The arrangement for recording gratings is shown in fig. 3 .

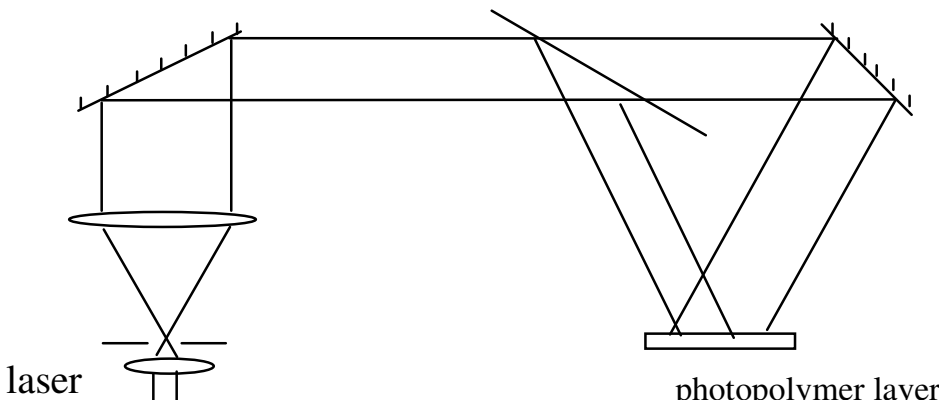

Fig. 3 Grating recording 
Bragg curves obtained at $1550 \mathrm{~nm}$ from unslanted gratings recorded at $532 \mathrm{~nm}$ are shown in Fig. 4. An EOS tunable laser was used at $1550 \mathrm{~nm}$. Its output was coupled into a single mode fibre with a collimating lens fitted to the fibre output end. The gratings were mounted on a vernier rotation stage.

Fig. 4a Bragg curve at $1550 \mathrm{~nm}$ for a grating recorded at $532 \mathrm{~nm}$. where the $532 \mathrm{~nm}$ beams are incident at $15^{0}$ and the $1550 \mathrm{~nm}$ beam at $49^{0}$ to the normal to the photopolymer layer. The efficiency of the grating at $1550 \mathrm{~nm}$ is $48 \%$ compared with $55.5 \%$ at $532 \mathrm{~nm}$.
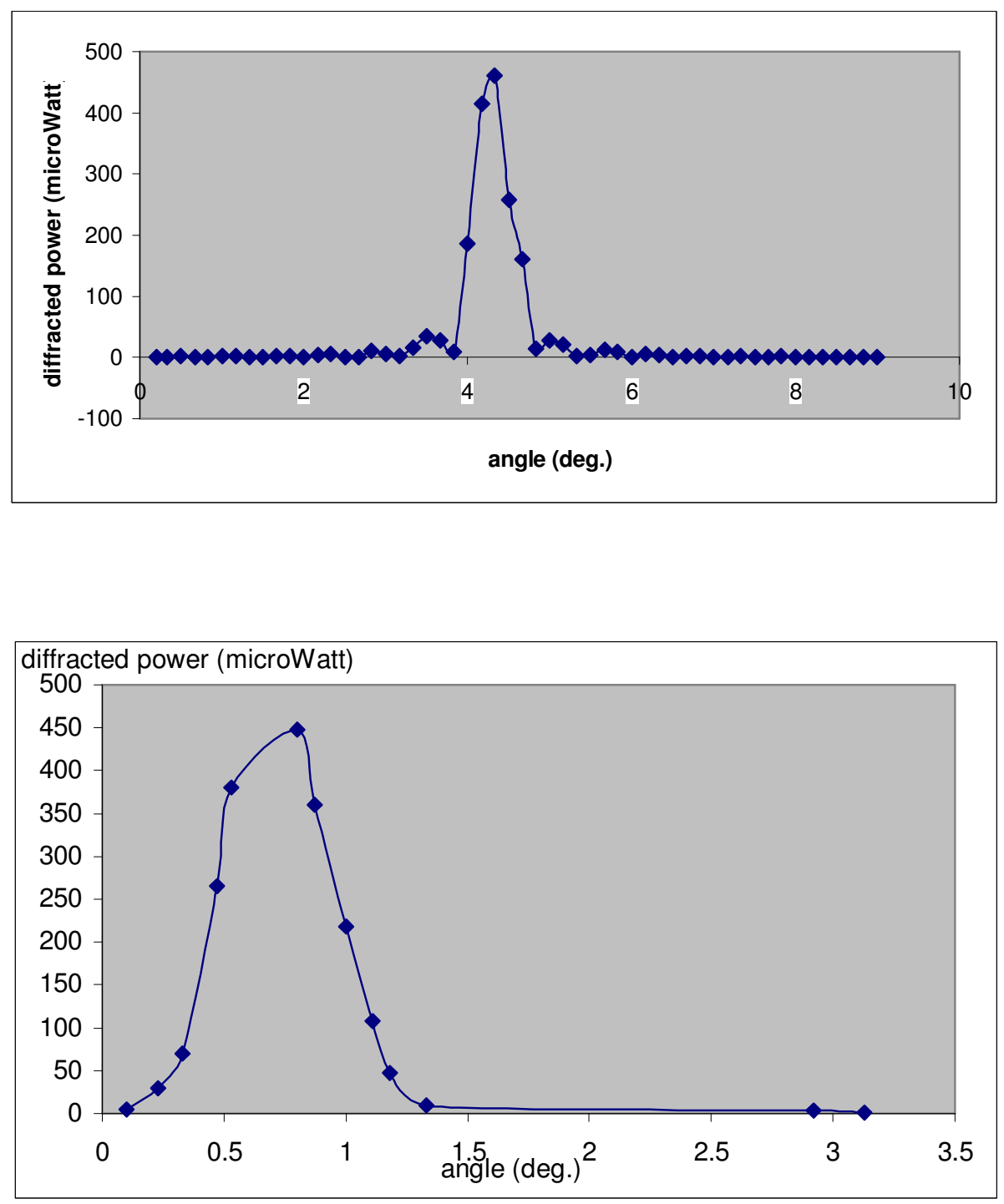

Fig. $4 \mathrm{~b}$ as $4 \mathrm{a}$. The efficiency of this grating at $1550 \mathrm{~nm}$ is $54.5 \%$ compared with $61.8 \%$ at $532 \mathrm{~nm}$.

These results show that the refractive index modulation of the gratings at $1550 \mathrm{~nm}$ compares favourably with the modulation at $532 \mathrm{~nm}$. We have not taken Fresnel losses into account in obtaining diffraction efficiency values. The difference between the diffraction efficiency at $1550 \mathrm{~nm}$ and that at $532 \mathrm{~nm}$ can by accounted for by higher Fresnel losses at the longer wavelength and higher angle of incidence. 


\subsection{Slanted gratings}

It has been demonstrated that slanted gratings may be recorded in the photopolymer system with acceptably low shrinkage of around $2 \%^{7}$, which enables us to trace the ray path of a $1550 \mathrm{~nm}$ beam illuminating a slanted grating recorded at $532 \mathrm{~nm}$.

Initially the $532 \mathrm{~nm}$ beams were incident on the layer at equal angles, $\theta$, on either side of the normal. The layer was then rotated by a small angle $\phi$ before recording so that the recorded fringes would be inclined at approximately $2 \phi / 3$ to the surface normal. By choosing appropriate values of $\theta$ and $\phi$, the $1550 \mathrm{~nm}$ beam can be made to emerge at very large angles to the layer normal or undergo total internal reflection at the substrate/air boundary.

The angle between the recording beams at the recording plane was $36^{\circ}$. The layer was rotated by $10^{0}$ before making the recording and the $1550 \mathrm{~nm}$ beam incident direction was chosen to ensure total internal reflection (fig. 5) .

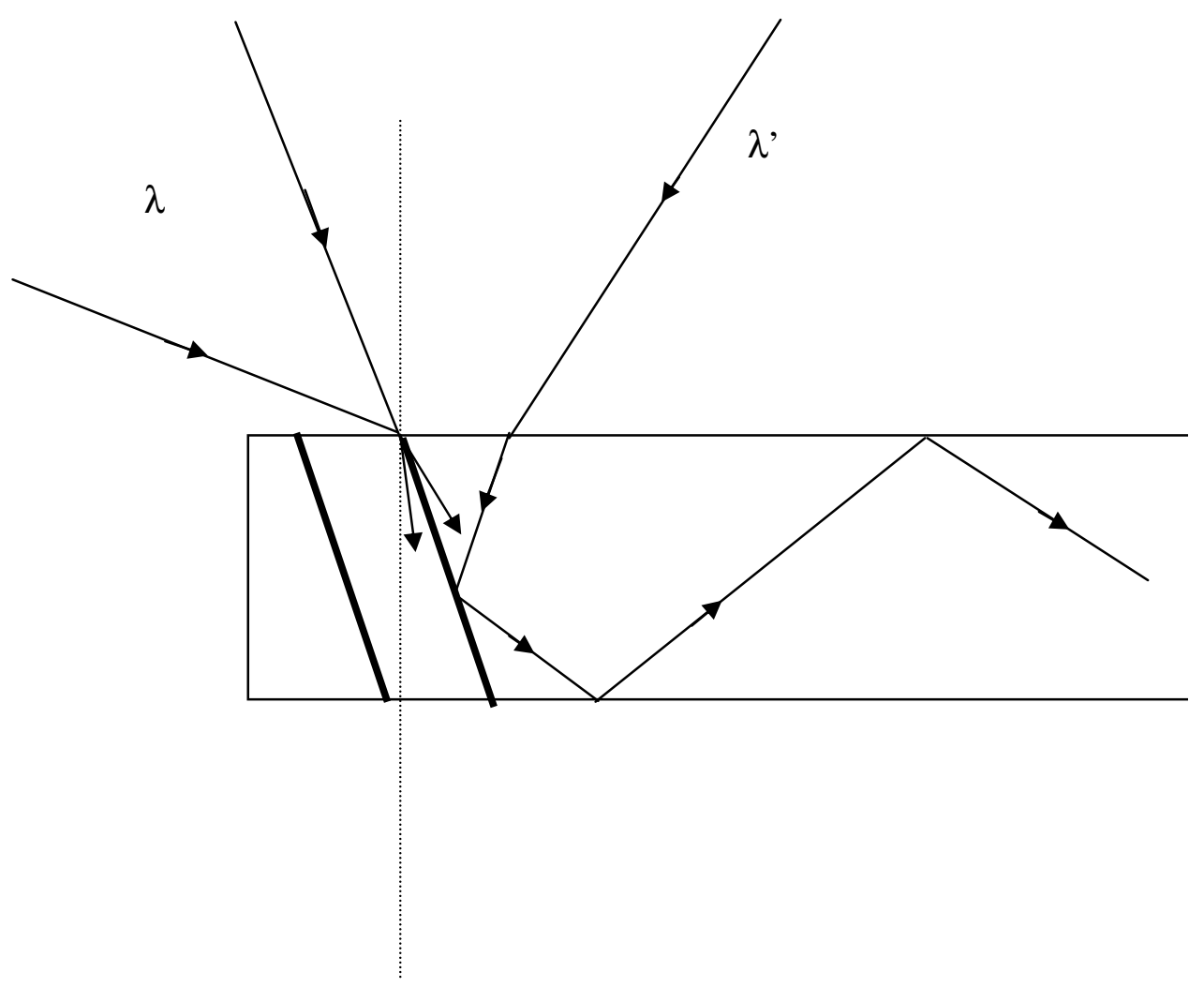

Fig. 5 Probe beam wavelength $\lambda$ ' coupled into photopolymer slanted grating recorded at wavelength $\lambda$

This was observed on an IR sensor card at the edge of the glass substrate. Because the diffracted beam was scattered through a substantial angle it was not possible to measure the power. Instead the power in the directly transmitted beam was monitored. Fig. 6 shows the result. 


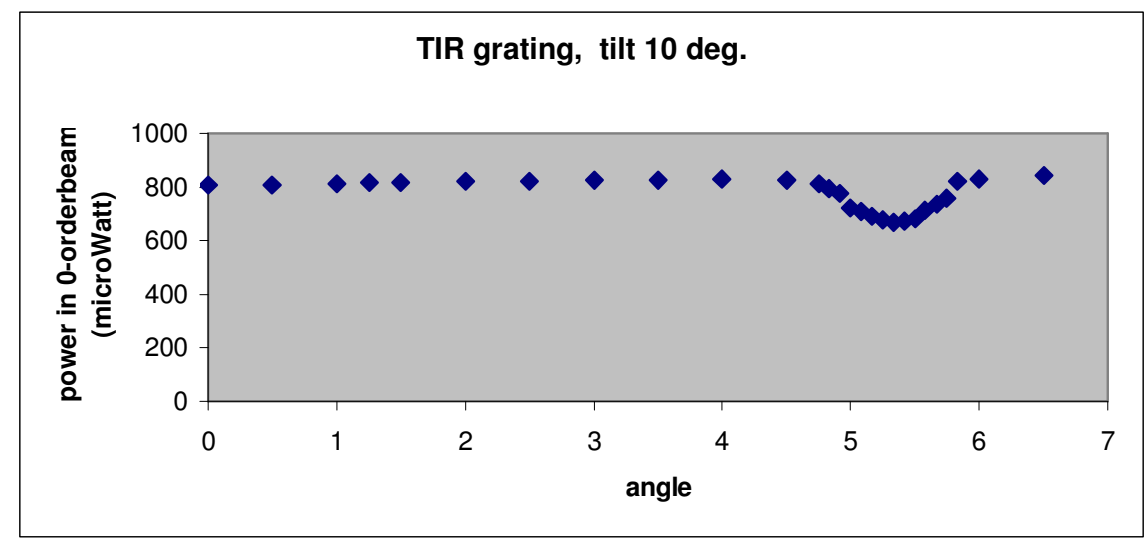

Fig. 6a Reduction in zero order power at Bragg angle. The efficiency at $1550 \mathrm{~nm}$ is $16 \%$

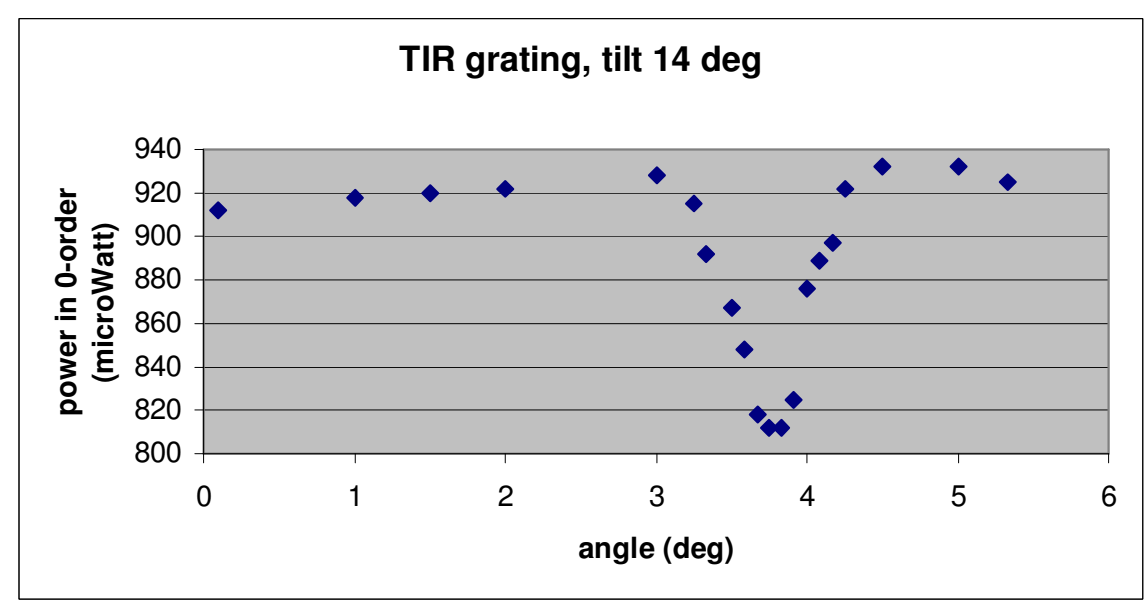

Fig $6 \mathrm{~b}$ Reduction in zero order power at Bragg angle. Efficiency is $12.5 \%$ at $1550 \mathrm{~nm}$.

Thus a slanted grating serves to couple an incoming light beam into what is effectively a slab waveguide.

It would be advantageous to have the $1550 \mathrm{~nm}$ beam normally incident and this was implemented using a larger tilt angle. Fig. 7 is an example of the result obtained.

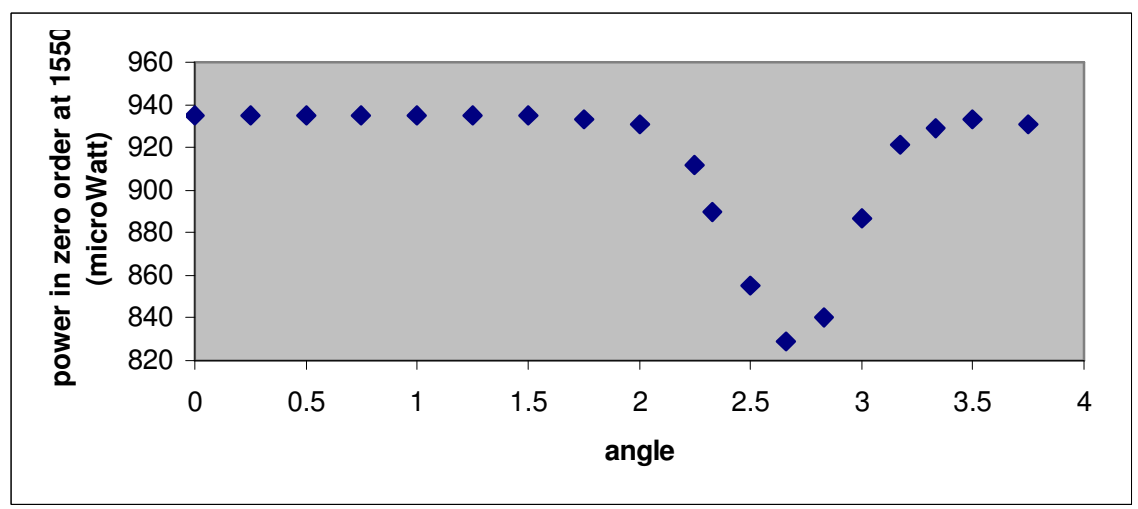

Fig. 7 Reduction in zero order power at Bragg angle for normally incident $1550 \mathrm{~nm}$ light. The efficiency is $6 \%$ at $1550 \mathrm{~nm}(47 \%$ at $532 \mathrm{~nm}$ ). The tilt angle is $35.5^{0}$. 


\subsection{Edge illuminated gratings.}

In this geometry unslanted gratings are recorded, whose fringe spacing is compatible with Bragg diffraction for a 1550 $\mathrm{nm}$ beam directed normally to the fringe planes. In this way the grating becomes a reflection grating at $1550 \mathrm{~nm}$. The interbeam angle for the writing beams is $62^{0}$ in air so that the spatial frequency of the grating is around 2000 lines $/ \mathrm{mm}$ which matches the midband wavelength of a broadband source (AFC BBS 1550) coupled to a $3 \mathrm{~dB}$ multimode fibre coupler. The unused port was immersed in index matching gel. The light reflected back into the fibre from the grating was passed to an optical spectrum analyser (ANDO AQ 6315B). Fig. 8 shows the arrangement with some results in Fig. 9 .

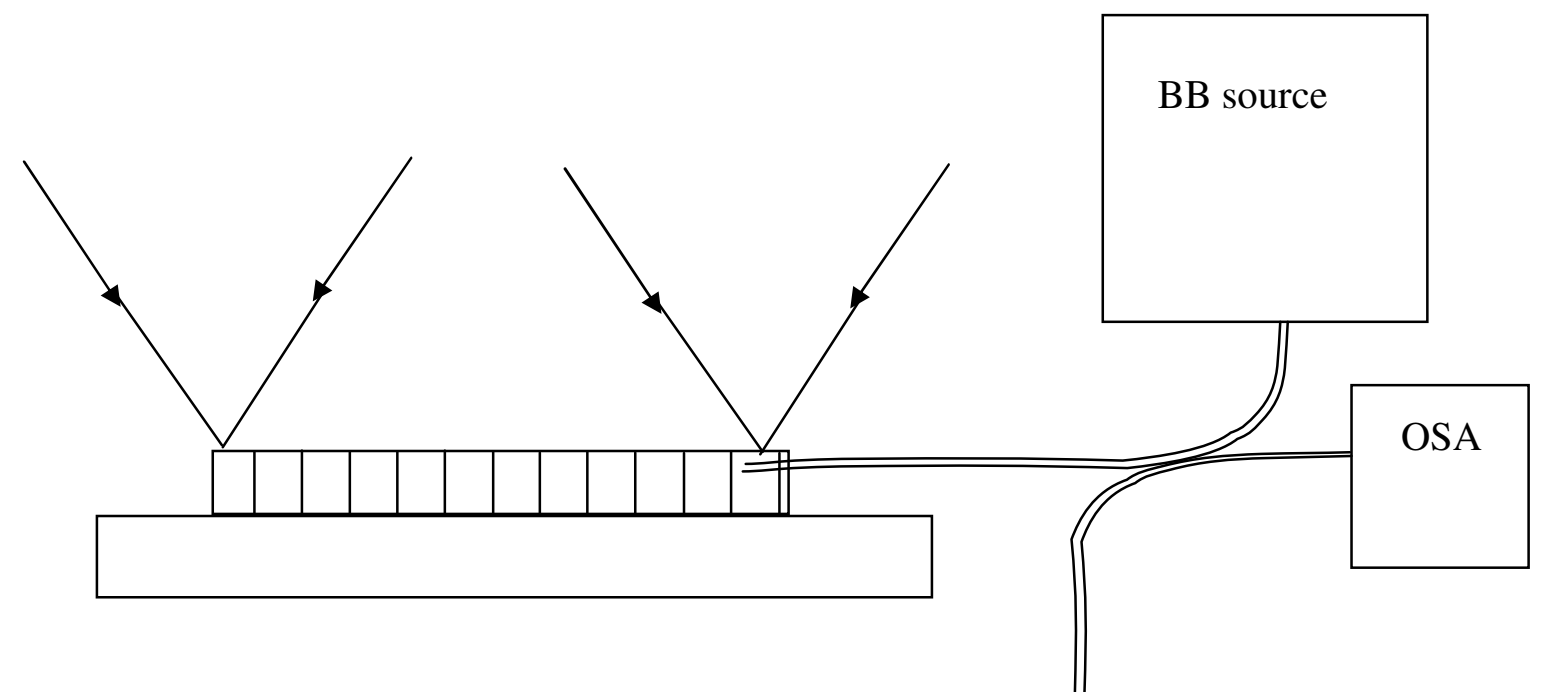

Fig. 8 Edge illumination of a transmission grating, BB broadband source, OSA optical spectrum analyser. The grating is mounted on a 3 axis translation/rotation stage.

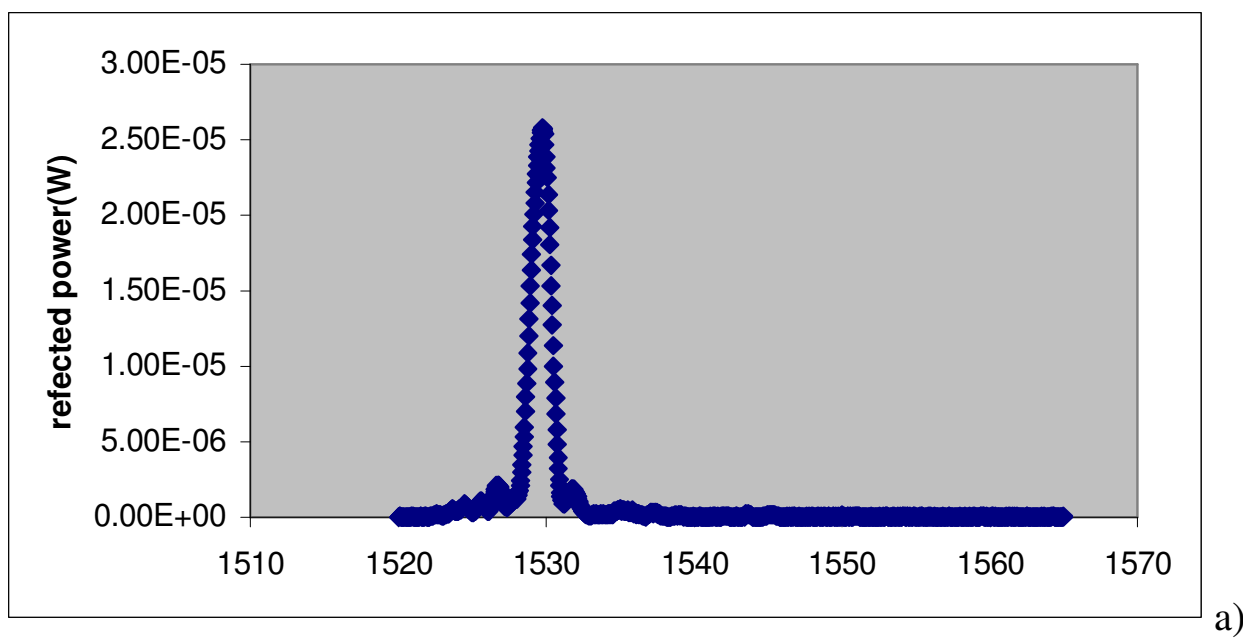



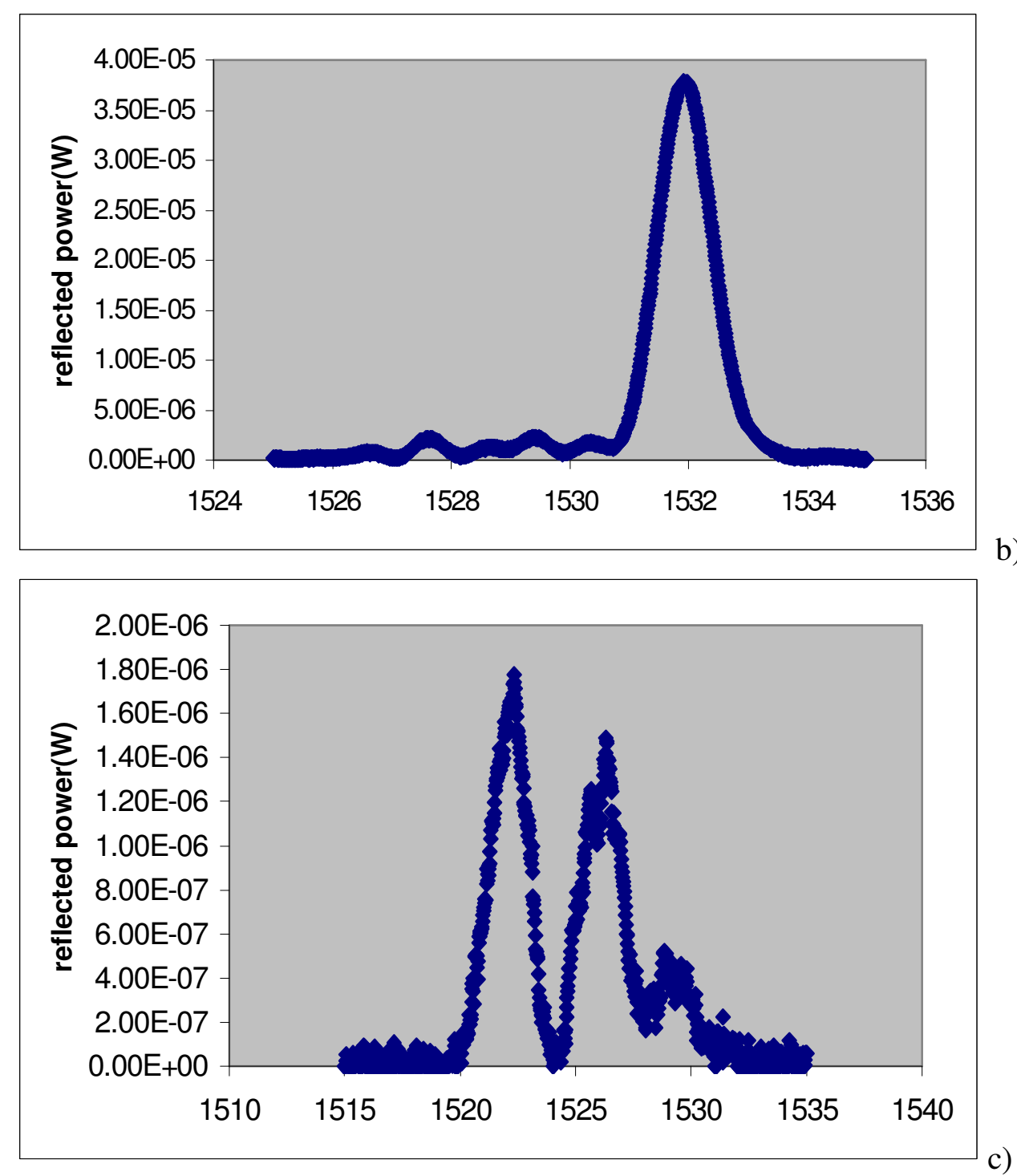

Fig. 9 Back reflected power from edge illuminated grating plotted against probe wavelength. a) typical curve b) a second grating peaking at $1532 \mathrm{~nm}$ c) over-modulated grating

The method used was to cut though the photopolymer layer using a sharp knife after recording the grating. The grating was then manipulated into contact with the tip of the illuminating fibre. To achieve this the grating was mounted on a 3axis translator combined with a 3-axis rotator. The grating edge and probe fibre tip were viewed through a binocular microscope. At close approach, Fabry-Perot oscillations were seen in the spectrum and, when the fibre came into contact with the grating, the back reflected power fell due to the absence of Fresnel reflection, until coupling to the reflection grating was achieved. Well defined Bragg curves were obtained in several cases. As the fibre was further pushed into the grating, the peak of the Bragg curve moved steadily towards shorter wavelengths, indicating compression of the grating. When the fibre direction was reversed, the peak movement also reversed. Over modulation effects were also observed (fig. 9c) 


\section{Discussion and conclusion}

We have demonstrated that holographically recorded gratings in acrylamide based photopolymer, using visible light of wavelength $532 \mathrm{~nm}$, can function as Bragg gratings at telecommunications wavelengths. Diffraction efficiencies of simple transmission gratings are as high at $1550 \mathrm{~nm}$ as at $532 \mathrm{~nm}$. We have also demonstrated coupling of $1550 \mathrm{~nm}$ light into a slab waveguide by using slanted gratings recorded in the photopolymer. Finally we have fabricated edge-lit Bragg gratings with good diffraction efficiency at $1550 \mathrm{~nm}$. The photopolymer material is low cost and easy to prepare.

In the case of gratings used as transmission gratings at around $1550 \mathrm{~nm}$, the Bragg curves all show angular widths of approximately $1.0^{0}$. One can compare this value with that predicted by the coupled wave theory for thick holograms.

Using the equation for the off-Bragg parameter $\chi_{r}{ }^{8}$

$$
\chi_{r}=\Delta \theta 2 \pi d \sin \theta_{0} / \lambda_{0}
$$

one can calculate the value of $\Delta \theta$ at which the normalised diffraction efficiency becomes zero $\left(\chi_{r}\right.$ in the range 2-3). $d$ is the grating thickness, typically $100 \mu \mathrm{m}, \lambda_{0}$ the wavelength in air and $\theta_{0}$, the Bragg angle in the photopolymer. Using the value of $49^{\circ}$ (Fig. 4 a) a value of $0.8^{0}$ is obtained for the full angular width of the grating in air, which agrees with the experimental angular width.

We may also obtain an estimate of the spectral bandwidth of the grating using the equation

where $\Delta \lambda$ is the wavelength shift at which the normalised diffraction efficiency becomes zero ( $\chi_{r}$ again in the range 2 -

$$
\chi_{r}=\Delta \lambda 2 \pi d \sin ^{2} \theta_{0} \cos \theta_{0} / n_{0} \lambda^{2}
$$

3). We obtain a spectral bandwidth of about $40 \mathrm{~nm}$.

In the case of edge illuminated gratings we can use the measured spectral bandwidth to determine the effective thickness of the grating used in reflection geometry. Using the appropriate form of the off-Bragg parameter for the reflection case

$$
\chi_{r}=\Delta \lambda 2 \pi n_{0} d \cos \theta_{0} / \lambda^{2}
$$

and a value of $\chi_{r}$ of 3.5 , we obtain a value of $\sim 1 \mathrm{~mm}$ for $d$. Thus only a very small length of transmission grating, recorded at $532 \mathrm{~nm}$ in this material, is needed in edge illuminated geometry at telecommunications wavelengths.

Acknowledegements: We thank Enterprise Ireland for the provision of an International Collaboration grant in support of this research.

\section{References}

1. O. Beyer, I. Nee, F. Havermeyer, and K. Buse, "Holographic Recording of Bragg Gratings for Wavelength Division Multiplexing in Doped and Partially Polymerized Polymethylmethacrylate", Appl. Opt. 42, 30-37 (2003)

2. S. Calixto, "Dry polymer for holographic recording”, App. Opt., 26, 3904-3910,1987 
3. S. Habraken, Y. Renotte, E. Stijns and Y. Lion, " Polarizing holographic optical elements in DuPont omnidex-TM films”, SPIE proceedings, Vol. 2532, pp. 9-14, 1995

4. M. Whelan, C. Forno, S. Martin, F. O’Neill and V. Toal, "Illumination systems using photopolymer gratings for speckle interferometry" Interferometry '99 International conference on optical metrology, techniques and technologies, Warsaw, Poland, 20th to 23rd September, 1999.

5. S. R. Guntaka, B. Bowe, V.Toal and S. Martin, "Holographic optical elements for combined holographic and digital speckle pattern interferometry” Speckle Metrology 2003, Trondheim, Norway, Proc. SPIE vol. 4933, eds. K. Gastinger, O.J.Lokberg \& S. Winther, 239-245,18-20 June 2003

6. S.R.Guntaka, V.Toal, and S.Martin, "Holographic and Electronic Speckle-Pattern Interferometry using a Photopolymer Recording Material”, Strain, 40, 2,79-81,2004

7. S. Martin PhD Thesis, University of Dublin, 1994

8. P. Hariharan, "Optical Holography, Principles, techniques and applications" Cambridge University Press, $2^{\text {nd }}$ edn. 1996 